\title{
Consumers' Perception on Information Overload in a Digital Society
}

\author{
Ruxandra Badescu ${ }^{1}$ and Bogdan Hrib ${ }^{2}$ \\ ${ }^{1) 2)}$ The Bucharest University of Economic Studies, Bucharest, Romania. \\ E-mail: ruxbadescu@gmail.com; bohrib@gmail.com
}

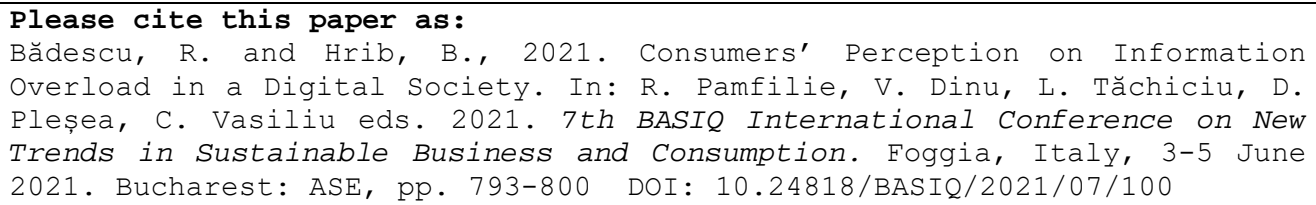

\begin{abstract}
Each consumer is confronted daily, 24 hours a day, to a real bombardment of information. They are assaulted by a flow of data and information that are frequently received from unknown sources without documentation, belonging to unknown authors without professional notoriety. The topic of the present information overload is of interest for both private consumers and for public or private organizations. We face information overload from the submission of a document in a public institution of the state to the daily activities, at home or at job. The objective of this article is to determine the differences and similarities in the perception of consumers regarding information overload on social media and in a digitalized society. The results of the discriminant analysis show that people older than 30 years did not find hard to get the information that is relevant to their needs from the excessive amount of information available on social media compared to the people younger than 30 years. The older consumers have also responded that they are not overwhelmed or distracted by the amount of information processed daily on social media compared to the young ones.
\end{abstract}

\section{Keywords}

Information overload, social media, digitalization, consumer, perception.

DOI: $10.24818 / B A S I Q / 2021 / 07 / 100$

\section{Introduction}

In our recent global context, with the permanent pressure of the COVID-19 health crisis it is common sense that all organizations must improve their digital skills. During the last year a long list of studies consider the move to digitalization (also including digital communication and digital innovation) the one-way to survive now and probably in the future. But this is only a one-way trip or there could be another way back or at least we can count on a long detour for some of parts from our global economy. Could the average clients, consumers, go forward like non-human entities or organizations? For sure, this will be the next issue for some years from now on.

The main goal is a better world for everybody - a world of sustainability for people, companies, civil society, environment - digitalization can be-seen as one of the enablers of the Circular Economy due to its building visibility and intelligence into products and assets such as knowledge of the location, condition and availability of assets (Antikainen, et al., 2018; Pelau and Acatrinei, 2019).

Digitalization has definitely many advantages regarding the increased efficiency of processes and activities allowing a better and easier communication between people. At the same time, digitalization comes with several disadvantages such as the phenomenon of information overload. With the constant connection to the digital environment, individuals and organization are constantly exposed to several information and social posts, which are difficult to handle on the long run. This paper starts with a literature review about the development of digitalization and its impact on the present society as well 
as the analysis of the information overload concept. In the second part of the paper, there are presented the results of a discriminant analysis about the perception of consumers of different ages on information overload. The results are interpreted and discussed, by giving further recommendations regarding this phenomenon.

\section{Literature review}

Digital transformation refers to the subscription to the use of digitization methods, digital communication and digital innovation. Annarelli, et al. (2021) define digitalization as the organizational capabilities that allow companies to pervasively combine digital assets and business resources, and leverage digital networks, to innovate products, services and processes for organizational learning and customer value creation and manage innovation for ensuring sustained competitive advantage. In order to handle the digital transformation in an effective manner, employees must work together in a new way, breaking down silos and collaboratively addressing cross-dimensional issues. Organizational members need to learn from each other in order to respond more quickly and consistently to changes in the market and within their own organization. Corporate cultures also need to move toward a digital mindset where innovation and quality is rewarded (Busu, 2019) and additional digital expertise can be brought in to help organizations to embrace the digital world and acquire the necessary skills and knowledge (Holmstrom, 2021).

Digital communication describes any electronic transmission of information that has been encoded digitally and transmitted via digital media (Grewal, et al., 2021). From the perspective of the future of the digital communication, two factors can have a major impact: how to understand the dynamic element of digital communication (the three level dynamics: the content of the message, the communicator and the interaction) and how to understand the multiple modalities of digital communication (Greval, et al., 2021).

The digital era is radically changing the way companies operate. As Holmstrom (2021) postulates, it must be clear that digitalization cannot occur without digitization. Digitization means the transition from analog data to digital formats. Digitization means the use of digitized information in work. Once the analog information has been digitized, it can be integrated and then used in various software applications with good premises for automation. The results would be seen in reducing costs, working time or processing of different types of activities in companies, in different streams (Holmstrom, 2021).

Companies must adapt their economic policies to this new challenge. The new position of companies among this new digital world and also the self-employment wave are some important but controversial issues for nowadays. Some empirical evidence suggests that the autonomy enabled by digitization is a key element that companies can leverage in their value chain upgrading (Oliviera, et al., 2021). Some authors revealed that digitalization has first a strong, negative effect determined by a significant connection between the process of digitalization in companies and self-employment rates. In the same time, there is no connection between digital adoption in companies and unemployment (Shapiro and Mandelman, 2021). This is not an issue generated and controlled by the local or global market. Public policies must focus on helping companies to understand the ways to convert the potential of the digital power into direct action and the policymakers may have decisive roles in helping organizations in this process of enacting digital power (Oliviera, et al., 2021).

From a managerial point of view, there are three different firm capabilities that have to be investigated in relation to the companies' process of digital innovation: knowledge generations capabilities, knowledge acquisition capabilities and market-sensing capabilities. Besides, the effect of social media relationships clearly suggest that in order to benefit from collaboration, networking agreements and open innovation, and particularly from knowledge inflows externally acquired and shared, innovativeness through digital innovation must be guaranteed in order to allow the exchange and sharing of knowledge and innovation (Tortora, et al., 2021).

A study from the early months of the COVID 19 pandemic analyzed how socio-demographics, living arrangement and internet experiences and skills related to increases or decreases in some digital communication methods. The study reveals inequalities emerging between people who are more and less 
privileged in their socio-economic status and depending on their internet skills and experiences (Nguyen, et al., 2021). This situation can be considered as a digital inequality and it can thus contribute to other axes of inequality placing a higher burden on already disadvantaged groups. They are the ones who are more likely to suffer worse consequences of the pandemic and who are likely to avoid them because of the digital communication (Nguyen, et al., 2021). But digital inequalities are not a separate part of the human society, they are not independent from the other sectors of humans - quality of life, poverty, rule of law, human rights, they have roots in the deep structure of the society and 'digital solutions' couldn't solve miraculously other fundamental issues like segregation or hegemony. Zheng and Walsham (2021) considers that technology designers and providers need to see the subjectivity of human beings behind the label of 'users' and consider genre, race, class, and other structural constraints individuals may face which condition their space of opportunities and capabilities, and thus how digital technology may impact their lives. Research has shown that there are several typologies of consumers based on their ability to accept new technologies and AI, the way they relate and trust to the received information and based on the impact of celebrity trend setter (Pelau, et al., 2021).

Besides these social inequalities, digitalization comes also with different access to information. Some may have limited access to information and digital resources, while others receive too much information, that they are not able to process. The term of information overload has been first used in 1964 (Gross, 1964) and it is more actual than ever. It was reset by Toffler (1973), who considered information overload as "the bewildering disorientation brought about by the premature arrival of the future". He considered that information overload might be the most important disease of the future, as any organism which succumbs to the pressure of environmental over-stimulation, the human mind and its decision-making processes will behave irrationally when overloaded Toffler (1973).

An individual can be confused by information overload. This could affect a person's ability to set priorities or could lead to poor decision making and dysfunctional performance. Another issue would be that information overload could cause anxiety or stress (Eppler and Mengis, 2004; Hu and Krishen, 2019). Based on these premises from various studies, information overload seems to cause more problems than would bring benefits to end users, whether they are individuals or entities (corporations, small and medium enterprises, institutions). This is one of the reasons why this research is a step into a bigger and deeper testing, investigation and experimentation on information overload topic.

Some authors associate the phenomenon of information overload with several negative connotations. Some consider it as an inflation of information. From both an economic and legal perspective, the term information inflation would be appropriate, at least from the perspective of its negative connotation (Doomen, 2009). Moreover, our lives today depend so much on new technologies that we have come to feel lost without a computer, internet and smartphone. Every day an invention comes to make our work easier, taking over especially from the mental effort we should make. Another almost similar term - information pollution - was coined by Nielsen (2003) and it applies to digital communications, such as e-mail, instant messaging and social media.

Digital media can also have negative effects on the cognitive capabilities of individuals. Spitzer (2020) investigates the negative influence that digital media can have on memory, concentration and cognitive abilities, especially of young people. He mentioned "the thicket of information" as being the explosion of information that pollutes the mental performance, thinking, critical ability and guidance of people, especially to young people (Spitzer, 2020) and even attention (Pelau, et al., 2020). A highly interactive environment for consumers in order to establish which information they would like to examine is offered by the Internet. A sense of control and empowerment is provided by this autonomy (Hua and Krishen, 2019).

\section{Methodology}

This research has the objective to determine the impact of the information overload in social media on consumer's behavior. The online questionnaire contained 10 items about different perceptions on information overload related to the difficulty of handling the amount of information (1 item adapted from Liu, et al., 2021; Swar, et al., 2017), the perception related to the huge quantity of information (4 items adapted from (Guo, et al, 2020; Zhang, et al., 2016), the overwhelming situation of handling the received information (3 items adapted from Lin, et al, 2021; Cao and Sun, 2018) and the feelings related 
to information overload (2 items adapted from Bahri, et al., 2020; Stephens, et al., 2017; Schrock, 2015). The items have been measured with the help of a 7-point Likert scale, having 7 for total agreement and 1 for total disagreement. The survey has been carried out in April 2021 and 131 respondents answered to these items. The Cronbach Alpha value of 0.909 determined the validity of the sample.

This paper is focusing on the differences of perception depending on age and on gender. From the total sample 72 were female and 59 were male respondents. Regarding the age, 66 respondents are younger than 30 years, while 65 were older than 30 years. The answers have been split in two groups: the ones which have been offered by persons under 30 years and the second ones which have been provided by persons older than 30 years. The major differences between the groups has been analyzed using SPSS 20.0, with the help of the discriminant analysis. In the following chapter are presented the results of the analysis.

\section{Results}

The research results related to the differences between consumers younger and older than 30 years are shown in Table no. 1. The results indicate that there are both similarities and differences between the answers given by those up to 30 years and those over 30 years. The differences are less than the similarities and refer to the greater concentration capacity of people over 30 years, compared to those under 30 years. Out of the 10 items, 3 showed that there were differences between the two selected age segments. The first difference is for IO05 which is related to the perception of the consumers regarding the difficulty with which the consumer obtains the information that is relevant to him/her from an excessive amount of information available on social media $(\mathrm{F}=5.962, \mathrm{p}=0.016)$. From here results that the mean of the perception for the people older than 30 years is lower (average $>30$ years $=4.10$ ) compared to the younger ones (average $<30$ years $=4.87$ ). This can be also observed from the results of item IO06 which shows that the younger people (average $<30$ years $=4.74$ ) are getting often more distracted by the excessive amount of information in social media compared with the people over 30 years (average $>30$ years $=4.16$ ). The second difference is related to the point IO06 which has the topic the easily distraction of attention when a greater load of information appears on social media $(\mathrm{F}=3.636$, $\mathrm{p}=0.059$ ). In this case, according to the responses, the perception regarding distraction due to information overload is higher for persons under 30 (average $<30$ years $=4.74$ ), while for people over 30 is lower (average $>30$ years $=4.16$ ). People over the age of 30 do not perceive that they feel just as overwhelmed by the overload of information on social media (average $>30$ years $=3.72$ ) compared to people under the age of 30 (average $<30$ years $=4.27$ ). This can be observed in the results of the item $\mathrm{IO} 07(\mathrm{~F}=3.112, \mathrm{p}=0.080)$.

Similar perception between the two groups can be observed at the first point of research IO01 regarding the way they can handle all the received information on social media effectively $(\mathrm{F}=1.255$, $\mathrm{p}=0.265>0.10$, average $<30$ years $=4.43$, average $>30$ years $=4.10$ ). Both groups consider at IO01 that there is too much information on social media $(\mathrm{F}=1.553, \mathrm{p}=0.215>0.10$, average $<30$ years $=5.50$, average $>30$ years $=5.83$ ).

Regarding the statement IO03, that the large amount of information on social media is difficult to manage, the two groups had the same perception $(\mathrm{F}=0.065, \mathrm{p}=0.798>0.10$, average $<30$ years $=4.66$, average $>30$ years $=4.58$ ). More similarities can be observed in the items IO04 and IO08 regarding the extraction of information from a multitude of information $(\mathrm{F}=1.855, \mathrm{p}=0.176>0.10$, average $<30$ years $=4.63$, average $>30$ years $=4.20)$ and its synthesis $(\mathrm{F}=0.042, \mathrm{p}=0.837>0.10$, average $<30$ years $=4.89$, average $>30$ years $=4.95$ ).

Moreover, the statements IO09 and IO10, referring to a condition, namely frustration $(\mathrm{F}=1.897$, $\mathrm{p}=0.171>0.10$, average $<30$ years $=4.54$, average $>30$ years $=4.07$ ) and the ability to process information $(\mathrm{F}=0.000, \mathrm{p}=0.990>0.10$, average $<30$ years $=4.27$, average $>30$ years $=427)$ show that there were no significant differences between the two groups. The last sentence IO10 has the same impact on all the respondents who were answering to this research. 
Table no. 1. Results regarding differences based on people's age

\begin{tabular}{|c|c|c|c|c|c|}
\hline & & $\begin{array}{l}\text { Aver- } \\
\text { age } \\
<30 \\
\text { years }\end{array}$ & $\begin{array}{l}\text { Aver- } \\
\text { age } \\
>\mathbf{3 0} \\
\text { years }\end{array}$ & $\mathbf{F}$ & $\mathbf{p}$ \\
\hline IO01 & $\begin{array}{l}\text { I cannot handle all the received information on social } \\
\text { media effectively. }\end{array}$ & 4.43 & 4.10 & 1.255 & .265 \\
\hline IO02 & There is too much information on social media & 5.50 & 5.83 & 1.553 & .215 \\
\hline IO03 & $\begin{array}{l}\text { I find the big amount of information on social media } \\
\text { as burden to handle }\end{array}$ & 4.66 & 4.58 & .065 & .798 \\
\hline IO04 & $\begin{array}{l}\text { I find it hard to extract important information from } \\
\text { the excessive amount of information available on so- } \\
\text { cial media }\end{array}$ & 4.63 & 4.20 & 1.855 & .176 \\
\hline IO05 & $\begin{array}{l}\text { I find it hard to get the information that is relevant to } \\
\text { my needs from the excessive amount of information } \\
\text { available on social media }\end{array}$ & 4.87 & 4.10 & 5.962 & .016 \\
\hline IO06 & $\begin{array}{l}\text { I am often distracted by the excessive amount of in- } \\
\text { formation in social media. }\end{array}$ & 4.74 & 4.16 & 3.636 & .059 \\
\hline IO07 & $\begin{array}{l}\text { I am overwhelmed by the amount of information that } \\
\text { I process on a daily basis from social media. }\end{array}$ & 4.27 & 3.72 & 3.112 & .080 \\
\hline IO08 & $\begin{array}{l}\text { I feel some problems with too much information in } \\
\text { social media to synthesize instead of not having } \\
\text { enough information. }\end{array}$ & 4.89 & 4.95 & .042 & .837 \\
\hline IO09 & $\begin{array}{l}\text { It frustrates me when I encountered overlapping in- } \\
\text { formation through various communication channels. }\end{array}$ & 4.54 & 4.07 & 1.897 & .171 \\
\hline IO10 & $\begin{array}{l}\text { I received more communication messages and news } \\
\text { than what I can process. }\end{array}$ & 4.27 & 4.27 & .000 & .990 \\
\hline
\end{tabular}

The second part of the research is showing the results obtained based on the analysis of similarities and discrepancies of answers considering the people's gender. These results can be observed in table no. 2 .

Table no. 2. Results regarding differences based on people's gender

\begin{tabular}{|c|c|c|c|c|c|}
\hline & & $\begin{array}{l}\text { Aver- } \\
\text { age } \\
\text { Fe- } \\
\text { male }\end{array}$ & $\begin{array}{l}\text { Aver- } \\
\text { age } \\
\text { Male }\end{array}$ & $\mathbf{F}$ & $\mathbf{p}$ \\
\hline IO01 & $\begin{array}{l}\text { I cannot handle all the received information on } \\
\text { social media effectively. }\end{array}$ & 4.38 & 4.13 & .721 & .397 \\
\hline IO02 & There is too much information on social media & 5.79 & 5.50 & 1.123 & .291 \\
\hline IO03 & $\begin{array}{l}\text { I find the big amount of information on social } \\
\text { media as burden to handle }\end{array}$ & 4.94 & 4.23 & 4.999 & .027 \\
\hline IO04 & $\begin{array}{l}\text { I find it hard to extract important information } \\
\text { from the excessive amount of information avail- } \\
\text { able on social media }\end{array}$ & 4.84 & 3.89 & 9.171 & .003 \\
\hline IO05 & $\begin{array}{l}\text { I find it hard to get the information that is relevant } \\
\text { to my needs from the excessive amount of infor- } \\
\text { mation available on social media }\end{array}$ & 4.88 & 4.01 & 7.643 & .007 \\
\hline IO06 & $\begin{array}{l}\text { I am often distracted by the excessive amount of } \\
\text { information in social media. }\end{array}$ & 4.91 & 3.89 & 12.088 & .001 \\
\hline IO07 & $\begin{array}{l}\text { I am overwhelmed by the amount of information } \\
\text { that I process on a daily basis from social media. }\end{array}$ & 4.45 & 3.44 & 11.211 & .001 \\
\hline
\end{tabular}




\begin{tabular}{|c|c|c|c|c|c|}
\hline & BASIQ INTERNATIONAL CONFERENCE & & & & \\
\hline IO08 & $\begin{array}{l}\text { I feel some problems with too much information } \\
\text { in social media to synthesize instead of not hav- } \\
\text { ing enough information. }\end{array}$ & 5.40 & 4.33 & 14.769 & .000 \\
\hline IO09 & $\begin{array}{l}\text { It frustrates me when I encountered overlapping } \\
\text { information through various communication } \\
\text { channels. }\end{array}$ & 4.76 & 3.76 & 9.043 & .003 \\
\hline IO10 & $\begin{array}{l}\text { I received more communication messages and } \\
\text { news than what I can process. }\end{array}$ & 4.62 & 3.84 & 5.690 & .019 \\
\hline
\end{tabular}

Source: Own research results

In the second part of the research, it can be observed that from 10 analyzed statements, 8 items (more than a half) show important differences, having $\mathrm{p}<010$ and 2 items are similar for both female and male. The first two items IO01 and IO02 mark the fact that between female and male are no differences regarding the perception on the management of the information received in social media $(\mathrm{F}=0.721$, $\mathrm{p}=0.397>0.10$, average female $=4.38$, average male $=4.13$ ) or on the fact that in social media there is too much information $(\mathrm{F}=1.123, \mathrm{p}=02.91>0.10$, average female $=5.79$, average male $=5.50)$. For the following items from IO03 until IO10 can be noted down the differences between answers provided by women and men. In regards to statement IO03, female perception (average female $=4.94$ ) compared with male perception (average male $=4.23)$ is higher $(\mathrm{F}=4.999, \mathrm{p}=0.027)$.

Finding hard to extract information from the available information on the social media $(\mathrm{F}=9.171$, $\mathrm{p}=0.003)$ and to get the necessary information relevant for their needs $(\mathrm{F}=7.643, \mathrm{p}=007)$ are behaviors that characterized women (average female $=4.84$, average female $=4.88$ ). Similar case is given by the answers provided to the items IO06, IO07 and IO09. Women (average female $=4.91$, average female $=445$, average female $=4.76$ ) compared to men (average male $=3.89$, average male $=3.44$, average male $=3.76$ ) have the perception that they can easily be distracted, overwhelmed and frustrated by the information overload on social media. Having problems with the information overload on social media to synthesize instead of not having enough information $(F=9.043, p=0.000)$ is a perception that defines the women (average female $=5.40$ ) more than men (average male=4.33). Even more differentiations are observed in IO10 at the perception for receiving more communication messaged and news than a person can process $(\mathrm{F}=5.690, \mathrm{p}=0.019$, average female $=4.62$, average male $=3.84)$.

\section{Conclusion}

The results of our research show both differences and similarities between the ways in which the two groups, people with age under 30 years and people with age over 30 years, women and men, perceive the effect of information overload in social networks and in the digital society. First of all, it can be deduced from the data analysis that young people (under 30) perceive information overload as a problem that distracts them from their daily tasks and makes it difficult for them to find information relevant to their needs. Although, both groups have the same perception that there is too much information online, on social media, those over 30 are not so often distracted and find the necessary information without being impacted by information overload.

Second of all, considering only age, there are no differences in respondents' perceptions of how information overload impacts emotional states. But, taking into consideration the genders, there can be observed a difference between women's perception and men's perception. For women, information overload has a greater impact than for men. They are getting distracted easily and find information on social media as being a burden to handle. Another important point to mention is that women, unlike men, feel frustrated when they encountered overlapping information through various communication channels.

Information overload could be considered an information pollutant for woman giving the fact that it has such a great impact on their behavior, namely that it is too difficult for them to manage it, representing a distraction from the information they actually need in order to perform a daily task or to make a decision. Another point that can be highlighted is that people with age over 30 years seem according to the results not paying so much importance on information overload. This observation can be also found in other researches, where older people have more experience of negative stimuli and this is the reason for they may react in a less negative manner (Ragu-Nathan, et al., 2008). 
In conclusion, this study's contribution was the finding that overload on social media leaves its mark on the behavior of women more than men, and this is a starting point for more detailed research about the factors that determines this status.

\section{References}

Annarelli, A., Battistella, C., Nonino, F., Parida, V. and Pessot, E., 2021. Literature review on digitalization capabilities: Co-citation analysis of antecedents, conceptualization and consequences. Technological Forecasting and Social Change, 166, Article number: 120635.

Antikainen, M., Uusitaloa, T. and Kivikytö-Reponena, P., 2018. Digitalisation as an Enabler of Circular Economy. Procedia CIRP, 73, pp.45-49.

Bahri, S., Fauzi, A. and Ahmad, N.S., 2020. A communication overload scale for use with mobile instant messaging in work management. Digital Business, 1, Article number: 100003.

Busu, M., 2019. Applications of TQM processes to increase the management performance of enterprises in the Romanian renewable energy sector. Processes, 7(10), Article number: 685.

Cao, X. and Sun, J., 2018. Exploring the effect of overload on the discontinuous intention of social media users: An S-O-R perspective. Computers in Human Behavior, 81, pp.10-18.

Doomen, J., 2019. Information Inflation. Journal of Information Ethics, 18(2), pp.27-37.

Eppler. M. and Mengis. J., 2004. The Concept of Information Overload: A Review of Literature from Organization, Science, Marketing Accounting, MIS, and related disciplines. The Information Society, 20(5), pp.325-344.

Grewal, D., Herhausen, D., Ludwig, S. and Villarroel Ordenes, F., 2021. The Future of Digital Communication research: Consiering dynamics and multimodality. Journal of Retailing, Article number: S0022435921000075.

Gross, B.M., 1964. The Managing of Organisations. New York: Free Press of Glencoe.

Guo, Y., Lu, Z., Kuang, H. and Wang, C., 2020. Information avoidance behavior on social network sites: Information irrelevance, overload, and the moderating role of time pressure. International Journal of Information Management, 52, Article number: 102067.

Holmstrom, J., 2021. From AI to digital transformation: The AI readiness framework, Business Horizons, Article number: S0007681321000744.

Hua, H. and Krishen, A.S., 2019. When is enough, enough? Investigating product reviews and information overload from a consumer empowerment perspective. Journal of Business Research, 100 , pp.27-37.

Lin, S., Lin, J., Luo, X. and Liu, S. 2021. Juxtaposed Effect of Social Media Overload on Discontinuous Usage Intention: The Perspective of Stress Coping Strategies. Information Processing and Management 58, Article number: 102419.

Liu, H., Liu, W., Yoganathan, V. and Osburg, V.S., 2021, COVID-19 information overload and generation Z's social media discontinuance intention during the pandemic lockdown. Technological Forecasting and Social Change, 166, Article number: 120600.

Nguyen, M.H., Hargittai, E. and Marler, W., 2021. Digital Inequality in Communication During A Time of Physical Distancing: The Case of COVID 19. Computers in Human Behavior, Article number: 106717.

Nielsen Norman Group, 1995. Coping with Information Overload, [online] Available at: $<$ https://www.nngroup.com/articles/coping-information-overload/> [Accessed 3 August 2020].

Oliviera, L., Fleury, A. and Fleury, M.T., 2021. Digital power: Value chain upgrading in an age of digitization. International Business Review, 30(3), Article number: 101850.

Pelau, C., Pop, M.I., Ene, I. and Lazar, L., 2021. Clusters of Skeptical Consumers Based on Technology and AI Acceptance, Perception of Social Media Information and Celebrity Trend Setter. Journal of Theoretical and Applied Electronic Commerce Research, 16(5), pp.1231-1247.

Pelau, C. and Acatrinei, C., 2019. The Paradox of Energy Consumption Decrease in the Transition Period towards a Digital Society. Energies, 12(8), Article number: 1428. 


\section{BASIQ INTERNATIONAL CONFERENCE}

Pelau, C., Badescu, R. and Negruțiu, C., 2020. A neuroscientific approach on the impact of information overload on consumers' attention. In: R. Pamfilie, V. Dinu, L. Tăchiciu, D. Pleșea, C. Vasiliu eds. 2021. 6th BASIQ International Conference on New Trends in Sustainable Business and Consumption. Messina, Italy, 4-6 June 2020. Bucharest: ASE, pp.723-729.

Ragu-Nathan, T., Tarafdar, M., Ragu-Nathan, B.S. and Tu, Q., 2008. The consequences of technostress for end users in organizations: conceptual development and empirical validation. Information Systems Research, 19(4), pp.417-433.

Schrock, A.R., 2015. Communicative affordances of mobile media: Portability, availability, locatability, and multimediality. International Journal of Communication, 9, pp.1229-1246.

Shapiro, A. F. and Mandelman, F.S., 2021. Digital adoption, automation, and labor markets in developing countries. Journal of Development Economics, 151, Article number: 102656.

Spitzer, M. 2020. Demență digitală. Bucharest: Humanitas.

Stephens, K.K., Mandhana, D.M., Kim, J.H.J., Li, X., Glowacki, E.M. and Cruz, I. 2017. Reconceptualizing communication overload and building a theoretical foundation. Communication Theory, 27(3), pp.269-289.

Swar, B., Hameed, T. and Reychav, I., 2017. Information overload, psychological ill-being, and behavioral intention to continue online healthcare information search. Computers in Human Behavior, 70, pp.416-425.

Toffler, A., 1973. Şocul Viitorului. Bucharest: Politică.

Tortora, D., Chierici, R., Farina Briamonte, M. and Tiscini, R., 2021. 'I digitize so I exist' Searching for critical capabilities affecting firm's digital innovation. Journal of Business Research, 129, pp.193-204.

Zhang, S., Zhao, L., Lu, Y. and Yang, J. 2016. Do you get tired of socializing? An empirical explanation of discontinuous usage behaviour in social network services. Information and Management, 53(7), pp.904-914.

Zheng, Y. and Walsham, G., 2021. Inequality of what? An intersectional approach to digital inequality under COVID-19. Information and Organisation, 21, Article number: 100341. 